(2) Open Access Full Text Article

\title{
Postoperative rhabdomyolysis following pars-plana vitrectomy under general anesthesia
}

This article was published in the following Dove Press journal:

Clinical Ophthalmology

31 July 2013

Number of times this article has been viewed

\section{John P Campbell' \\ Cobin Soelberg ${ }^{2}$ \\ Andreas K Lauer ${ }^{\prime}$}

'Retina Division, Casey Eye Institute, Oregon Health and Science University, Portland, OR, USA; '2Division of Anesthesiology, Oregon Health and Science University, Portland, OR, USA
Correspondence: John P Campbell Casey Eye Institute, Retina Division, Oregon Health and Science University, 3375 SW Terwilliger Blvd, Portland, OR 97239, USA

Tel + I 503494 789|

Fax +I 5034947233

Email johnpetercampbell@gmail.com
Importance: Rhabdomyolysis is a known, but rare, complication of general anesthesia. To the authors' knowledge, it has never before been reported following an ocular surgery, and we could find no similar cases in the surgical literature following any brief surgical procedure. We believe this case to be unique in those regards and aim to raise awareness among ophthalmologists of this postoperative complication, as timely intervention can prevent renal failure and death.

Observations: We report the case of a 58-year-old male who developed rhabdomyolysis following vitrectomy for retinal detachment repair under general anesthesia. The patient had several risk factors for this complication including morbid obesity, type II diabetes mellitus, and American Society of Anesthesia class III risk profile. His postoperative course was notable for significant myalgias in the postoperative recovery area, followed several hours later by oliguria, "root beer" colored urine, and a markedly elevated creatinine kinase level. He was hospitalized for two days for intravenous hydration and monitoring of his renal function and has fully recovered.

Relevance: As the prevalence of obesity and type II diabetes mellitus increase worldwide, ophthalmologists need to be aware of the signs and symptoms of postoperative rhabdomyolysis. Treatment often requires inpatient hospitalization to prevent the associated morbidity and mortality.

Keywords: rhabdomyolysis, general anesthesia, vitrectomy, retinal detachment, obesity, diabetes

\section{Case report}

We report the case of a 58-year-old obese man who developed rhabdomyolysis after vitrectomy for rhegmatogenous retinal detachment under general anesthesia. His past medical history was remarkable for a 15-year history of type II diabetes mellitus $\left(\mathrm{A}_{1 \mathrm{c}}\right.$ [glycosylated hemoglobin] 7.6\%), hypertension, gastroesophageal reflux disease, benign prostatic hypertrophy, obstructive sleep apnea, and obesity (weight $155 \mathrm{~kg}$ and body mass index $41 \mathrm{~kg} / \mathrm{m}^{2}$ ). His medications included doxazosin, finasteride, glipizide, insulin, metformin, valsartan, fenofibric acid, and over-the-counter vitamins. He had no previous personal or family history of anesthesia complications.

His ocular history was notable for bilateral pseudophakia and ocular hypertension, and he was referred to our center for a macula-sparing rhegmatogenous detachment in his right eye. He was taken to the operating room. His preoperative blood glucose was 107, and his American Society of Anesthesiologist classification was III. In the operating room, the patient was placed in the supine position with gentle restraints on his arms and legs to keep his arms on the operating table comfortably. After 
light anesthesia consisting of $100 \mathrm{mcg}$ fentanyl and $40 \mathrm{mg}$ propofol, a retrobulbar injection with a 50:50 mixture of $2 \%$ lidocaine and $0.75 \%$ bupivicaine was administered. An initial attempt was made to perform the procedure under monitored anesthesia care; however, the patient expressed feelings of claustrophobia and the decision was made to proceed with general anesthesia. He was given additional $250 \mathrm{mg}$ propofol and $140 \mathrm{mg}$ succinylcholine with cricoid pressure held for a rapid sequence induction and was intubated utilizing a video laryngoscope, without complication. Anesthesia was maintained with desflurane with an end-tidal concentration between $5 \%$ and $6 \%$. There were no intraoperative signs of malignant hyperthermia or hypermetabolism. The surgery was uncomplicated and lasted approximately 1 hour.

In the recovery room, the patient complained of muscular pain and cramping in both arms, shoulders, legs, and chest and repeatedly rubbed these areas with his hands as if to try to provide relief. He was treated for presumed succinylcholine associated myalgias with $30 \mathrm{mg}$ intravenous ketorolac. He was discharged after his pain diminished, approximately 60 minutes after the completion of his procedure, and he was instructed to maintain face-down positioning. At approximately 5:30 am the next morning he notified the on-call physician that he was having difficulty urinating and had "root beer" colored urine. He was referred to the emergency room where he was noted to have a creatinine kinase level of 67,000 IU/L. He was admitted for intravenous hydration and hospitalized for 2 days. His creatinine kinase peaked at 137,000 IU/L approximately 30 hours after surgery, and trended down over the next week, but his renal and hepatic function remained within normal limits.

Postoperative rhabdomyolysis is a rare complication of general anesthesia. ${ }^{1-3}$ Myoglobinuria can lead to renal failure, which is associated with up to $20 \%$ mortality. ${ }^{4}$ It is most commonly associated with morbidly obese patients following prolonged surgical procedures such as bariatric surgery, and risk factors in that setting include body mass index $>40 \mathrm{~kg} / \mathrm{m}^{2}$, diabetes, American Society of Anesthesiologist III or IV risk, and duration greater than 4 hours. ${ }^{2}$ To our knowledge, it has never before been reported following

Clinical Ophthalmology

\section{Publish your work in this journal}

Clinical Ophthalmology is an international, peer-reviewed journal covering all subspecialties within ophthalmology. Key topics include: Optometry; Visual science; Pharmacology and drug therapy in eye diseases; Basic Sciences; Primary and Secondary eye care; Patient Safety and Quality of Care Improvements. This journal is indexed on

Submit your manuscript here: http://www.dovepress.com/clinical-ophthalmology-journal ocular surgery, or after such a brief surgical procedure. As intraoperative positioning is a risk factor for rhabdomyolysis (due to muscle compression under bodyweight), it is interesting to speculate whether postoperative positioning (following vitrectomy) may functionally prolong the procedure and increase the risk of developing rhabdomyolysis in susceptible patients, though our patient exhibited symptoms immediately in the recovery area. As the prevalence of obesity and type II diabetes increase worldwide, and more obese patients require ocular surgery, signs and symptoms of rhabdomyolysis should be familiar to all members of the operating team, especially since early treatment with intravenous hydration can mitigate the morbidity and mortality associated with the disease.

\section{Contributions}

JC was responsible for the data collection, management, preparation, review, and approval of the manuscript. CS and AL contributed to the review and approval of the final manuscript. There were no funding sources for this brief observational report.

\section{Permissions}

The patient described in this case report is aware of this publication and has provided written, informed consent for its publication, though the manuscript has no personal health information or identifiable information.

\section{Disclosure}

The authors have no relevant financial interests or conflicts of interest in the subject matter of this article.

\section{References}

1. Ankichetty S, Angle P, Margarido C, Halpern SH. Case report: Rhabdomyolysis in morbidly obese patients: anesthetic considerations. Can J Anaesth. 2013;60(3):290-293.

2. Lagandré S, Arnalsteen L, Vallet B, et al. Predictive factors for rhabdomyolysis after bariatric surgery. Obes Surg. 2006;16(10):1365-1370.

3. De Tommasi C, Cusimano MD. Rhabdomyolysis after neurosurgery: a review and a framework for prevention. Neurosurg Rev. 2013;36(2): 195-202; discussion 203.

4. Holt SG, Moore KP. Pathogenesis and treatment of renal dysfunction in rhabdomyolysis. Intensive Care Med. 2001;27(5):803-811.

PubMed Central and CAS, and is the official journal of The Society of Clinical Ophthalmology (SCO). The manuscript management system is completely online and includes a very quick and fair peer-review system, which is all easy to use. Visit http://www.dovepress.com/ testimonials.php to read real quotes from published authors. 